\title{
Estão nossos jovens doentes? Percepções de adolescentes em relação à saúde em dois municípios gaúchos
}

| ' Fabiana de Oliveira Chaise, ${ }^{2}$ Simoní Assunção Soares, ${ }^{3}$ Stela Nazareth Meneghel |

Resumo: $\mathrm{O}$ artigo procurou compreender os significados atribuídos à saúde por adolescentes, na faixa etária entre 11 a 13 anos, e quem eles consideram seu cuidador de saúde. $\mathrm{O}$ estudo foi realizado com estudantes de escolas pública e privada, dos municípios de Sapucaia do Sul/RS e Porto Alegre/RS. As informações foram obtidas por meio de um questionário semi-estruturado. Os depoimentos indicaram que os jovens da escola pública consideram a família como o agente de cuidado à saúde, enquanto que os da escola privada consideram apenas a mãe. Observou-se, também, que para os estudantes da escola pública, saúde está relacionada com bemestar físico e mental, enquanto que para os da instituição privada é somente ausência de doenças. Estes achados auxiliam a um melhor entendimento dos conceitos de saúde dos adolescentes, identificando seus cuidadores e servindo para subsidiar as práticas educativas e sanitárias.

Palavras-chave: adolescência, saúde, cuidado.

\footnotetext{
1 Acadêmica do Curso de Fisioterapia da Universidade do Vale do Rio dos Sinos Unisinos - São Leopoldo/RS. Endereço eletrônico: fabianachaise@gmail.com

2 Acadêmica do Curso de Fisioterapia da Universidade do Vale do Rio dos Sinos Unisinos - São Leopoldo/RS. Endereço eletrônico: simoni84@yahoo.com.br

${ }^{3}$ Professora do Programa de Pós-Graduação em Saúde Coletiva da Universidade do Vale do Rio dos SinosUnisinos - São Leopoldo/RS. Pós-Doutora em Psicologia Social. Pesquisadora CNPq. Endereço eletrônico: smeneghel@hotmail.com
}

Recebido em: 12/11/2007. Aprovado: 17/09/2008. 


\section{Introdução}

A população de jovens brasileiros, no ano de 2003 , representa $20 \%$ da população geral, o que corresponde a um total de quase 35 milhôes de adolescentes, sendo $50,43 \%$ do sexo masculino e $49,57 \%$ do feminino. Aproximadamente $80 \%$ dos adolescentes vivem no meio urbano (IBGE, 2000). A lei brasileira de no 8.069/ 1990 - Estatuto da Criança e do Adolescente - estabelece como adolescência a faixa etária compreendida dos 12 aos 18 anos.

A adolescência é uma fase de desenvolvimento entre a infância e a fase adulta, marcada por mudanças que envolvem os aspectos físicos, sexuais e emocionais dos jovens. Pode ser caracterizada, também, como sendo uma fase de reorganização e de preparo para a entrada na vida adulta (ASSIS et al., 2003; ADORNO, 2005).

As necessidades de saúde na adolescência excedem os aspectos orgânicobiológicos. Esta situação remete à criação de políticas de saúde do adolescente com a finalidade de prestar atendimento, promover a saúde, identificar vulnerabilidades e reabilitar. Esses programas, como o Prosad (Programa Saúde do Adolescente), criado em 1989 pelo Ministério da Saúde, embora vise ao princípio da integralidade, não foi suficiente para romper com um enfoque clínico e assistencialista. Assim, a ineficácia desses programas e de outros serviços de saúde pode ser devida, entre outros aspectos, ao grau de adequação aos objetivos propostos e à homogeneização das metas, sem considerar as características econômicas, culturais e sociais dos adolescentes (LEÃO, 2005).

Segundo Carlini-Cotrim et al.(2000), as pesquisas sobre a saúde dos adolescentes brasileiros ainda se concentram nas questôes ligadas à gravidez precoce e ao uso de anticoncepcionais. Isso ocorre devido à percepção que a sociedade tem dos jovens, pois o encaram como um problema e não como um potencial para o desenvolvimento. Com isso promovem apenas ações de controle, através de medidas sanitárias com caráter autoritário e intervencionista, na maioria das vezes baseadas no modelo médico hegemônico focado na doença. Dessa forma, houve dificuldade em obter artigos para este estudo, pois poucos autores abordam outros aspectos relacionados à vida do adolescente, como por exemplo, hábitos alimentares, prática de exercícios físicos, sociabilidades e até mesmo sofrimento mental. Isso demonstra que o jovem, atualmente, é caracterizado como um grupo homogêneo e não percebido em sua singularidade. 
Os jovens pouco utilizam os serviços de saúde, e suas necessidades muitas vezes passam despercebidas pelos profissionais da área da saúde. Assim, pode-se notar uma desconexão entre esses serviços e os adolescentes, pois de um lado os jovens resistem a se aproximar das instituiçóes de saúde; por outro, os serviços apresentam dificuldades para acolhê-los, especialmente quando a questão ultrapassa as patologias centradas no corpo físico (LEÃO, 2005). O objetivo desta pesquisa foi entender os significados atribuídos à saúde por um grupo de adolescentes de $11 \mathrm{a}$ 13 anos e apontar quem consideram seus cuidadores de saúde.

\section{Metodologia}

A opção por uma metodologia qualitativa nos leva a compreender as possíveis relações dos adolescentes com sua saúde e o contexto social no qual vivem os estudantes de escola pública e privada, através da análise de seus discursos. A análise do discurso considera as formas impressas tanto em textos, quanto em imagens como componentes existentes nas práticas e vivências sociais, permitindo a interpretação e caracterização do cenário descritivo e explicativo dos indivíduos, servindo de meio para avaliar a eficácia do processo comunicativo imediato (SERRA, 2003).

A pesquisa, de cunho qualitativo, foi realizada com 51 adolescentes na faixa etária de 11 a 13 anos, estudantes da $5^{\mathrm{a}}$ e $7^{\mathrm{a}}$ séries do ensino fundamental. Foram escolhidas duas escolas, uma de ensino público estadual, que comporta 610 alunos e atende à população de baixa renda, situada em Sapucaia do Sul, região metropolitana de Porto Alegre.

Sapucaia do Sul é uma cidade com 132.672 habitantes, sendo que 4,23\% da população de homens e 3,96\% da população de mulheres estão na faixa etária entre 10 a 14 anos (FEE, 2006). O município possui 20 escolas estaduais, sendo 12 de ensino fundamental, atendendo a 14.182 estudantes. Em relação à saúde, são disponibilizados à população 17 postos de saúde, um Centro de Saúde Mental, uma Clínica de Saúde da Mulher, uma Unidade Central de Especialidades e um hospital, havendo também um Serviço de Assistência à Criança e ao Adolescente, criado pela Secretaria da Assistência Social em 2002. O município apresenta um PIB per capita de R\$13.347, aparentemente elevado, mas existe um grande percentual de população de baixa renda.

A outra escola selecionada foi de ensino privado, situada no município de Porto Alegre, capital do Rio Grande do Sul. A instituição existe há 79 anos e atende à 
população de classe média, sob a direção de uma ordem religiosa. Atualmente, o colégio oferece Educação Infantil, Ensino Fundamental e Ensino Médio. Porto Alegre possui 1.415.237 habitantes, sendo que 3,65\% da população de homens e 3,43\% da população de mulheres estão na faixa etária entre 10 a 14 anos (FEE, 2006). O município possui 582 instituições de ensino privado e 262 de ensino estadual. No ano de 2005, o valor médio do gasto com saúde pelo SUS em Porto Alegre foi de R \$231,00 por habitante.

Para aplicação da pesquisa foi contatada, primeiramente, a coordenação pedagógica de cada escola e exposto o objetivo do estudo. Após a aceitação das instituiçôes, marcou-se o dia da realização da entrevista com os adolescentes. A coleta de depoimentos foi realizada sob forma de questionário semi-estruturado contendo quatro perguntas. As entrevistas foram realizadas em sala de aula, na presença da professora de ciências de cada escola. Cada jovem preencheu o questionário identificando a idade e a série, tendo a opção de identificar ou não o instrumento. Utilizou-se a linguagem escrita para manter a individualidade e a privacidade do jovem, para que ele pudesse manifestar, sem constrangimentos, seus conhecimentos sobre saúde, doença e cuidado, considerando os jovens como informantes fidedignos de sua realidade (VICTORA, 2000). Ao término da prática e de posse dos 51 questionários devidamente preenchidos pelos estudantes, iniciamos o processo de sistematização de dados, ou seja, a identificação das respostas mais citadas. Estas foram agrupadas, permitindo a facilitação do processo de discussão dos achados. A análise das informações procurou entender significados, sentidos e associações informados pelo adolescente em suas respostas.

\section{Resultados}

Foram entrevistados 25 alunos da escola privada, sendo nove meninas e 16 meninos com média de idade de 11,03 anos e 26 alunos da escola pública, sendo 13 meninos e 13 meninas com média de idade de 12,4 anos. A escolha de duas instituições diferenciadas de ensino nos permite comparar as diferentes visões e características do estudante adolescente em relação aos conhecimentos de saúde, doença e cuidado. Assim, pode-se verificar a relação entre o significado que o jovem dá para sua saúde, doença e cuidado, e como esses significados permitem a compreensão das possíveis associaçôes entre cuidado e família, doença e sintomas físicos e as estratégias para a prevenção e tratamento. A linguagem do adolescente, 
na interpretação destas questôes (quadro 1), identifica as relações sociais de seu cotidiano, bem como a construção de conhecimento a partir de seu contexto sociocultural e sua visão de realidade (MEDRADO, 1999). No agrupamento dos dados, houve o cuidado de preservar as categorias mais citadas na ordem descrita pelos jovens. Isso pode ser notado na questão "quem cuida de você quando fica doente?", onde cada aluno poderia indicar apenas um ou uma seqüência de cuidadores, e na questão "o que você faz para melhorar quando fica doente?", onde cada adolescente enumerou os recursos terapêuticos utilizados. Esses resultados são demonstrados no quadro 2.

Quadro 1 - Questionário aplicado em adolescentes na faixa etária entre 11 a 13 anos nos município de Sapucaia do Sul/RS e Porto Alegre/RS

1. O que é ter saúde para você?

2. Quem cuida de você quando fica doente?

3. Você consegue perceber quando seu corpo está doente?

4. O que você faz para melhorar quando fica doente?

Quadro 2 - Percepçóes sobre saúde/doença e cuidador, Porto Alegre e Sapucaia do Sul, 2007

\begin{tabular}{|l|c|c|}
\hline & Escola Pública Estadual & Escola Privada \\
\hline $\begin{array}{l}\text { O que é ter saúde para } \\
\text { você? }\end{array}$ & $\begin{array}{c}\text { Sentir-se bem, felicidade e } \\
\text { alegria }\end{array}$ & $\begin{array}{c}\text { Ausência de doença, } \\
\text { alimentação e esportes. }\end{array}$ \\
\hline $\begin{array}{l}\text { Quem cuida de você } \\
\text { quando fica doente? }\end{array}$ & Família & Mãe, pais e médico. \\
\hline $\begin{array}{l}\text { Você consegue perceber } \\
\text { quando seu corpo está } \\
\text { doente? Se a resposta for } \\
\text { SIM, o que identifica como } \\
\text { mudança? }\end{array}$ & Sim. Indisposição & Sim. Indisposição \\
\hline $\begin{array}{l}\text { O que você faz para } \\
\text { melhorar quando fica } \\
\text { doente? }\end{array}$ & Chá, remédio e repouso & Medicamento e repouso \\
\hline
\end{tabular}




\section{Quem cuida do adolescente pertencente à escola pública?}

As respostas obtidas nos depoimentos dos alunos da escola pública nos mostraram que o cuidado é realizado preponderantemente pela família: "Quando fico doente quem me cuida é minha mãe, meu pai, minha avó e minha dinda”. (CA 11 anos); "Quem me cuida é minha mãe, meu pai e meu irmão". (MIR 11 anos). Nota-se também que o cuidado descrito não é dispensado somente pelos pais, mas também pelos outros integrantes do grupo familiar, como por exemplo, irmãos, avós e tios. Por outro lado, na sociedade atual, frente à desagregação dos sistemas estatais de proteção e seguridade social e a precarização do trabalho, constata-se que a adolescência tem sido prolongada e as famílias estão suprindo necessidades e cuidados antes fornecidos pelas instituições. Essa situação nos indica que o cuidado também tem a função - tanto na infância, na adolescência ou na fase adulta, quanto na saúde, na enfermidade ou na morte - de suprir as carências humanas e estimular a vida na esfera familiar, como forma de estabelecer vínculos e manifestações de afeto (SCHMITT, 2003).

A procura por auxílio médico foi citada pelos alunos da escola pública como dependente da "gravidade" da doença, e eles mencionaram o uso de chás como coadjuvantes no restabelecimento da saúde: "Quando fico doente, tomo chá e deito na cama ou senão tomo remédio" (F, 10 anos). Pode-se observar, nessa resposta, a busca por formas alternativas de tratamento, demonstrando carência de recursos financeiros ou de acesso aos serviços de saúde por parte dessa população. Sob esse enfoque, destacam-se as práticas curativas domésticas, que utilizam recursos naturais retirados da natureza como fornecedoras de base terapêutica para o sistema de cura, apresentando baixo custo. Essa é uma forma de tratamento diversificado que dá oportunidade de escolha ao paciente, podendo expressar, muitas vezes, sua forma de vida, seus valores e sua cultura (LUZ, 2005). A procura por essas práticas também pode refletir a insatisfação dos usuários perante o sistema médico vigente pautado na investigação de patologias acompanhada de exames complexos e caros, considerando o adoecimento como uma questão biológica, sem relevar os aspectos psicossociais, símbolos e representações de saúde (LUZ, 1996). Outro aspecto que vale ressaltar é a dificuldade de acesso aos serviços de saúde, incluindo tempo de espera excessiva. Nas famílias de baixa renda, o cuidado é repartido entre todos os integrantes do grupo familiar que se responsabilizam ou se revesam para tratar do jovem doente. 


\section{O cuidador na visão dos alunos da escola privada}

Para os alunos da escola particular, observou-se que no papel do cuidador está a mãe: "Quem me cuida quando fico doente é minha mãe, mas se fico muito doente vou ao médico" (RS, 12 anos). Nesse discurso, pode-se observar que na situação de enfermidade o jovem associa o cuidado com a figura materna.

$\mathrm{Na}$ sociedade patriarcal, a atribuição do cuidado dos filhos, do marido e dos idosos continua onerando as mulheres. As mulheres de camadas médias da população, como as mães dos adolescentes dessa escola, parecem sobrecarregadas, tanto pelos relatos dos adolescentes, quanto pelos relatos informais dos professores O aumento do número de famílias monoparentais chefiadas por mulheres agudiza ainda mais essa situação. Esse fato pode fazer com que elas recorram preponderantemente, nos casos de adoecimento dos filhos, ao uso de medicação como forma terapêutica para sanar esses processos.

Os adolescentes da escola privada nos afirmaram que quando ficam doentes, usam medicamento: "Para melhorar tomo remédio e fico de repouso" (MBM, 12 anos). O recurso do medicamento induz ao imediatismo terapêutico, provocando o fenômeno da medicalização - ou seja, o uso de medicamentos como alternativa para a melhoria dos sintomas e das doenças.

Segundo Tesser (2006), a medicalização transforma culturalmente as populações, ocasionando declínio da capacidade de enfrentamento da maior parte dos adoecimentos - ou seja, a perda da situação de autonomia vivenciada pelo ser humano, desestimulando-o a ser o responsável por sua saúde ou sua doença e levando-o ao consumo abusivo de serviços biomédicos. A utilização de medicamentos pode ser analisada não somente como uma estreita dependência do usuário voltada para o controle das enfermidades, mas também como pressão do mercado capitalista ao consumo. A exploração do valor simbólico do medicamento pela mídia pode levar à indução de mau uso, propiciando reaçôes de insensibilidade, de inconsciência, de dependência e de apatia provocadas artificialmente (ILLICH, 1975).

\section{Percepção da doença entre os adolescentes de ambas as escolas}

Os adolescentes de ambos os grupos participantes do estudo demonstram perceber quando estão doentes através da indisposição que a enfermidade provoca: "Sinto cansaço, a falta de vontade e o mal-estar"(NB, 12 anos); "Percebo a doença quando 
acordo muito cansada ou quando há mudanças repentinas na rotina, sinto dores no corpo e febre" (TO, 12 anos). Eles disseram ser capazes de diagnosticar-se e perceber quando o corpo está emitindo sinais de doença, indicando autoconhecimento e autonomia.

No entanto, a autonomia não pode ser vista separadamente da dependência gerada quando há a doença, pois nessa etapa necessitamos do cuidado dos outros, seja o conhecimento especializado de um profissional, seja afeto e apoio emocional dos amigos e familiares (SOARES, 2007). Numa conversa informal com alguns professores da escola privada, obtivemos a informação de que alunos chegam diariamente na escola com prescrição para fazer uso de medicamentos, pois apresentam alta prevalência de dores, como por exemplo, na cabeça e no estômago. Essas ocorrências levaram a escola a organizar, em seu espaço físico, um núcleo de saúde para atender esses jovens. O núcleo de saúde é terceirizado e dispõe de um nutricionista, dois fisioterapeutas, um psicólogo, uma fonoaudióloga e uma terapeuta ocupacional que trabalham integradamente, atendendo alunos e funcionários da escola. Os educadores também mencionaram que esse núcleo foi criado na tentativa de melhorar os hábitos e a qualidade de vida desses jovens, através de seus conhecimentos, para que eles possam construir concepções de saúde que atendam a suas necessidades, pois é nessa fase da vida que o jovem se torna suscetível a informações, impressões e atitudes de cuidado à saúde (ALMEIDA, 1999). Esses dados revelam que nossos jovens estão adoecendo facilmente e, como um meio de combater essas enfermidades, seria necessário identificar suas carências, através de uma escuta que respeite as representações e as condições de vida de cada adolescente, ajudando-os a lidar com as angústias e transformaçóes de corpo que acompanham essa etapa da vida (ADORNO et al., 2005; CAMPOS et al., 2003).

\section{O que é ter saúde para esses jovens?}

Identificou-se que, para cada grupo analisado, as concepções de saúde são diferentes. Para os alunos da escola pública: "Ter saúde é ser feliz com si mesmo e se cuidar" (FD, 11 anos); "Saúde é paz, alegria e coisas que fazem bem a vida" (AL, 11 anos); "Saúde é estar viva em todas as horas" (FSA, 12 anos). Já para os alunos da escola privada: "Saúde é não ter nenhuma doença, ter uma alimentação saudável, e fazer bastante exercício" (TS, 13 anos); "Saúde é estar livre de doenças me sentindo bem e me alimentando corretamente" (AVM, 12 anos). 
De acordo com Adorno et al.(2005), a adolescência não se caracteriza como um fenômeno homogêneo, mas de processos sociais distintos de construção de cada jovem, abarcando os aspectos econômicos, sociais e culturais. Isso pode ser observado nas respostas apresentadas acima, onde as formas de pensar são diferenciadas: enquanto que para alguns saúde é sentir-se bem, um estado de espírito, para outros é a ausência de doença, o que reflete a influência da cultura e do meio no qual o jovem está inserido (LUZ, 1996).

A transmissão cultural não se faz presente apenas nas famílias, mas também nos meios de comunicação em massa, que atualmente determinam como o indivíduo deve agir, pensar e falar, provendo muitas vezes a inversão ou a distorção dos conceitos de saúde. Esta situação oferece incertezas e apreensões sobre o modo de se conduzir, o que pensar e o que sentir, podendo gerar repercussóes concretas na saúde dos jovens das diversas sociedades (LUZ, 2005). Pode-se notar, também, que para ambos os grupos de adolescentes entrevistados há uma noção, mesmo que incipiente, sobre o aspecto holístico da saúde, de que a mente e o corpo não se dissociam. Essa circunstância foi evidenciada quando os alunos significaram saúde associando-a à paz, à felicidade, à alimentação saudável e ao exercício físico (BENSON, 1980).

\section{Considerações finais}

Analisando as respostas dadas pelos jovens, verificou-se que os estudantes da escola pública indicaram como cuidador da saúde a família, enquanto que os da escola particular indicaram somente a mãe e o médico. Pode-se observar que as doenças fazem parte do cotidiano dos adolescentes e o quanto as práticas medicalizadoras os atingem cada vez mais. Os hábitos adquiridos e as circunstâncias vivenciadas indicam o sentido dado pelos jovens às sensaçóes corporais, mostraram que eles sabem diagnosticar seus problemas de saúde e que conhecem quando as coisas não andam bem. Além disso, possuem noções integrais sobre saúde, percebendo suas múltiplas dimensões.

A análise da realidade em que os jovens vivem propicia, com o auxílio de profissionais da área da saúde, a construção de práticas educativas e de promoção à saúde que possam potencializar suas habilidades e atitudes em relação à vida. 


\section{Referências}

ADORNO, Rubens de Camargo Ferreira; ALVARENGA, Augusta Thereza; VASCONCELLOS, Maria da Penha Costa. Jovens, trajetórias, masculinidades e direitos. São Paulo: Fapesp, 2005.

ALMEIDA, Anecy de Fátima Faustino. De menina a mãe adolescente: uma construção de vulnerabilidade de gênero. Campo Grande: UFMS, 1999.

ASSIS, Simone et al. A representação social do ser adolescente: um passo decisivo na promoção da saúde. Ciência \& Saúde Coletiva. Rio de Janeiro, v. 8, n.3, p. 669-680, 2003.

BENSON, Herbert. Medicina Humanista: a ciência do comportamento para uma saúde melhor. São Paulo: Brasiliense, 1980.

CAMPOS, Juliana Álvares Duarte Bonini; ZUANON, Ângela Cristina Cilene; GUIMARÃES, Murilo de Souza. Educação em saúde na adolescência. Rev. Cienc Odontol Brás. São Paulo, v.6, n. 4, p. 48-53, 2003.

CARLINI-COTRIM, Beatriz; GAZAL-CARVALHO, Cynthia; GOUVEA, Nelson. Comportamento de saúde entre jovens estudantes. Rev Saúde Pública. São Paulo, v. 34, n. 6, p. 636-45, 2000.

FUNDAÇÃO DE ECONOMIA E ESTATÍSTICA. Secretaria de Estado da Coordenação e Planejamento. Estado do Rio Grande do Sul, 2006. Dados populacionais. Disponível em: http:// www.fee.rs.gov.br >. Acesso em: set. 2007.

ILLICH, Ivan. A expropriação da Saúde. Nêmesis da medicina. Rio de Janeiro: Nova Fronteira, 1975.

INSTITUTO BRASILEIRO DE GEOGRAFIA E ESTATÍSTICA. Censo Demográfico 2000. Rio de Janeiro. Disponível em: http://www.ibge.gov.br. Acesso em: 20 nov. 2006.

LEĀO, Luciana de Melo Souza. Saúde do adolescente: atenção integral no plano da utopia. 2005. 180p. Dissertação (Mestrado em Saúde Pública) - Fundação Osvaldo Cruz Centro de Pesquisas Aggeu Magalhães - Departamento de Saúde Coletiva, Recife, 2005.

LUZ, Madel T. A arte de curar versus a ciência das doenças: história social da homeopatia no Brasil. São Paulo: Dynamis Editorial, 1996.

Cultura contemporânea e medicinas alternativas: novos paradigmas em saúde no fim do século XX. Physis: Rev. Saúde Coletiva, Rio de Janeiro, 15 (supl.), p. 145-176, 2005.

MEDRADO, Benedito. Práticas discursivas e produção de sentidos no cotidiano: aproximaçōes teóricas e metodológicas. São Paulo: Cortez, 1999.

SCHMITT, Carlos Altemir. Concepçôes e práticas de cuidado humano no cotidiano de uma organização: uma configuração ética e estética de vida no espaço laboral. 2003. 171p. Dissertação (Mestrado em Engenharia de Produção) - Engenharia de Produção da Universidade Federal de Santa Catarina, Florianópolis, 2003. 
SERRA, Giani Moliari Amaral; SANTOS, Elisabete Moreira. Saúde e mídia na construção da obesidade e do corpo perfeito. Ciência \& Saúde Coletiva, Rio de Janeiro, v. 8, n. 3, p. 691-701, 2003. SOARES, Jussara Calmon Reis de Souza Soares; CAMARGO JR, Kenneth Rochel. A autonomia do paciente no processo terapêutico. Interface: Comunic, Saúde, Educ. São Paulo, v. 11, n. 21, p. 65-78, 2007.

TESSER, Charles Dalcanale. Social medicalization (I): the exaggerated success of modern 'epistemicide' in health. Interface: Comunic, Saúde, Educ. São Paulo, v. 10, n. 19, p. 61-76, 2006. VICTORA, Ceres Gomes; KNAUTH, Daniela Riva; HASSEN, Maria de Nazareth Agra. Pesquisa qualitativa em saúde: uma introdução ao tema. Porto Alegre: Tomo editorial, 2000. 
Adolescents' health perceptions in two cities of Rio Grande do Sul state, Brazil

In this paper we tried to understand the meaning adolescents, ages 11 to 13 years, attribute to health and who they consider their health care agent. The study was carried out among students from public and private schools, in the cities of Sapucaia do Sul and Porto Alegre, Rio Grande do Sul State. Information was collected through a semi-structured questionnaire. The answers indicated that the youngsters from the public school consider the family their health care agent, while in the private school they said it was their mothers. It was also noticed that for public school students, health is related with mental and physical welfare, while for students from the private institution it is the absence of illness only. Such findings help better understand the adolescents' health perceptions, identifying their health care agent and subsidizing educational and sanitary practices.

> Key words: adolescence, health, care. 